\title{
Transferência de renda condicionada e o trabalho do cuidado: uma análise do Programa Bolsa Família em 2019
}

\author{
Jéssica Alves de Lima Germine* \\ Roberta Guimarães Peres ${ }^{\star \star}$
}

\begin{abstract}
Os programas de transferência de renda condicionada têm como público-alvo famílias em situação de vulnerabilidade e são pagos preferivelmente às mulheres. A crítica feminista em relação a tais programas argumenta que, ao se direcionarem os benefícios às mulheres, papéis sociais baseados na divisão sexual do trabalho são reforçados, o que gera uma sobrecarga feminina com o trabalho doméstico e do cuidado. Este artigo investiga a relação entre a titularidade feminina e o uso do tempo com o trabalho do cuidado, comparando mulheres e homens que recebem e que não recebem o benefício do Programa Bolsa Família. Para isso, foram analisados os dados disponíveis na Pesquisa Nacional por Amostra de Domicílios Contínua de 2019. Os resultados mostram que as mulheres beneficiárias que cuidam de crianças de até cinco anos despendem mais horas do que todos os outros grupos. Contudo, os homens beneficiários que cuidam de crianças nessa faixa etária gastam menos horas do que os beneficiários que não cuidam.
\end{abstract}

Palavras-chave: Transferência de renda. Desigualdades de gênero. Trabalho doméstico. Divisão sexual do trabalho.

\footnotetext{
* Universidade Federal do ABC (UFABC), São Bernardo do Campo-SP, Brasil (jessica.germine@ufabc.edu.br; https://orcid. org/0000-0002-8786-4084).

** Universidade Federal do ABC (UFABC), São Bernardo do Campo-SP, Brasil (roberta.peres@ufabc.edu.br; https://orcid. org/0000-0003-1001-8047).
} 


\section{Introdução}

As famílias são o foco de diversos programas de combate à pobreza, não só no Brasil, mas em vários países que os utilizam como mecanismo para reduzir as desigualdades socioeconômicas. 0 combate à pobreza diz respeito não apenas ao alívio dos seus sintomas mais urgentes, mas também ao rompimento com a reprodução intergeracional das condições de pobreza. Nesse processo, o trabalho do cuidado é parte fundamental. A interrupção do chamado ciclo intergeracional da pobreza depende desse conjunto de atividades que envolvem alimentar, dar banho, ajudar nas tarefas escolares, oferecer suporte afetivo e psicológico ao núcleo familiar, em especial crianças, idosos, pessoas com deficiências e enfermas. 0 cuidado, assim, é essencial para o sucesso desse tipo de programa, tanto por sua importância para a reprodução da vida, quanto por estar relacionado ao cumprimento das condicionalidades que permitiriam a superação das condições de pobreza.

A ênfase na unidade familiar, contudo, tem levantado ponderações cautelosas com relação ao possível caráter reforçador das desigualdades de gênero que esses programas gerariam, uma vez que as mulheres são, na maioria das vezes, as pessoas de referência dos domicílios atendidos por tais políticas e, assim, são responsabilizadas pelo cuidado com os membros da família. Enquanto representante do domicílio, a mulher torna-se ponte entre Estado e família, responsável tanto por manter o cadastro familiar atualizado, quanto por garantir que as exigências dos programas sejam cumpridas, as quais podem incluir atividades como levar as crianças para acompanhamentos de saúde regulares e imunizações, bem como assegurar que crianças e adolescentes tenham a presença escolar mínima estabelecida nas diretrizes da política. Ao eleger as mulheres como pessoas de referência das famílias, a ação da política em termos de redução das desigualdades econômicas seria potencializada, porém, apresentaria alguns custos relacionados ao reforço dos papéis sociais de gênero.

No Brasil, falar em desigualdades econômicas significa, necessariamente, prover um perfil que tem raça e gênero bem definidos. Afinal, 71,2\% das mulheres negras adultas encontram-se numa situação de extrema pobreza, pobreza ou vulnerabilidade, ao passo que, entre os homens brancos, esse percentual é de 46,2\%, segundo dados de 2015 (IPEA, 2017). Assim, mesmo as políticas públicas de alívio da pobreza que têm alcance universal acabam provocando efeitos maiores sobre essa população. Este é o caso do Programa Bolsa Família (PBF), que direciona os benefícios à mulher cadastrada como pessoa de referência do domicílio, e que hoje atende a mais de 14 milhões de famílias (BRASIL, 2020a). Entre os beneficiários do programa, cerca de $73,7 \%$ são pretos e pardos (CAMARGO et al., 2013).

0 desenho do programa é inovador no sentido de conectar diferentes frentes de objetivos a uma transferência de renda mensal. Ao exigir contrapartidas das famílias para manutenção dos benefícios, o Bolsa Família busca melhorar as condições de saúde e educação das famílias pobres, com foco nas crianças, adolescentes, gestantes e nutrizes, a fim de romper o ciclo intergeracional da pobreza (BRASIL, 2020b; MEDEIROS; BRITTO; 
SOARES, 2007). A titularidade feminina, contudo, tem gerado produtivo debate sobre a essencialização dos papéis femininos na condição de mães e cuidadoras das suas famílias, bem como os possíveis efeitos - positivos e negativos - sobre as mulheres beneficiárias.

Levando isso em conta, o presente trabalho investiga de que forma a titularidade feminina pode representar um reforço dos padrões de gênero derivados da divisão sexual do trabalho, em especial sobre o trabalho do cuidado, considerando que raça e classe são, também, marcadores que influenciam as vivências e experiências das beneficiárias do programa. Para tanto, foi realizada uma investigação sobre as horas dedicadas ao trabalho doméstico e ao cuidado, com base nos dados disponíveis na Pesquisa Nacional por Amostra de Domicílios Contínua (PNAD Contínua) realizada em 2019. Foram comparados os resultados para homens e mulheres de famílias beneficiárias e não beneficiárias do PBF, de acordo com a raça autodeclarada na pesquisa.

Este trabalho está dividido em cinco seções, além dessa introdução. A primeira traz um panorama das discussões sobre a divisão sexual do trabalho e os agravamentos decorrentes de classe e raça no Brasil. Em seguida, expõe-se de que forma tal divisão social do trabalho influenciou o desenho do PBF, bem como pesquisas anteriores que já buscaram compreender de que forma a titularidade feminina influencia a posição das mulheres beneficiárias. Posteriormente são detalhados os procedimentos metodológicos realizados na pesquisa e apresentam-se os resultados obtidos e os discute à luz dos debates teóricos trazidos anteriormente. Por fim, são tecidas as considerações finais do trabalho.

\section{A divisão sexual do trabalho e o trabalho do cuidado no Brasil}

A distribuição de tarefas com base no gênero é conhecida na teoria feminista como divisão sexual do trabalho (KERGOAT, 2009). Esta distribuição das ocupações é arranjada e estruturada por um sistema em que o trabalho feminino é expropriado das mulheres, com base numa responsabilização assimétrica das atividades essenciais para a reprodução da vida. Tais critérios, no entanto, estão ancorados numa visão binária do sexo (BIROLI, 2018). Eles se baseiam em interpretações essencialistas, atribuindo características e comportamentos aos indivíduos de acordo com o seu gênero.

Tal separação das ocupações passa também pela delimitação dos espaços em que elas são realizadas. Dessa forma, nos espaços públicos, frequentemente percebidos como universais e homogêneos, estão inseridas as relações de produção, bem como o debate político. Em contraposição, aos espaços privados, percebidos como individuais, são designados os assuntos relativos à casa e à família (MARIANO; CARLOTO, 2011). A separação dual entre as esferas pública e privada não é mero acaso: serve para camuflar as relações de poder cotidianas, silenciando os conflitos existentes nas relações familiares e trabalhistas (MIGUEL; BIROLI, 2014).

É nessa lógica dicotômica que os papéis tradicionais de gênero foram construídos e reproduzidos. Ao serem designados papéis diferentes aos indivíduos sob o critério das 
diferenças sexuais, construiu-se a ideia de que assuntos tidos como "privados", como é o caso do trabalho doméstico, são do universo feminino. Esse tipo específico de divisão social do trabalho tem dois princípios: o da separação e o da hierarquia. Pelo princípio da separação, entende-se que as atividades são designadas aos indivíduos de acordo com os sexos. Já o princípio da hierarquia coloca um valor maior ao trabalho executado pelos homens (HIRATA; KERGOAT, 2007). Como consequência, homens e mulheres ocupam os espaços públicos com diferente status: enquanto eles são vistos como cidadãos e trabalhadores, as mulheres estão inseridas em tais espaços pelas atividades relacionadas à maternidade e ao cuidado, ou seja, características ligadas ao universo privado (MARIANO; CARLOTO, 2011).

Por se tratar de uma atividade voltada à família e, assim, desenvolvida no âmbito privado, o trabalho do cuidado foi definido como uma extensão do trabalho doméstico e, por consequência, atribuído também às mulheres (BIROLI, 2018). Esta atividade envolve o tempo e a energia gastos com o cuidado com as crianças, os idosos, as pessoas adoecidas e aquelas com deficiência (BIROLI, 2018). Embora possa ser exercido fora de casa e de forma remunerada, em grande parte este trabalho é realizado dentro do próprio domicílio (ou de uma comunidade) e envolve laços familiares e afetivos (MIGUEL; BIROLI, 2014; BIROLI, 2018).

Por frequentemente englobar relações íntimas, como as familiares, o cuidado ainda encontra dificuldade para ser incluído no debate público como uma atividade essencial para a reprodução da vida (BIROLI, 2018). Herrero (2013) salienta que a vida humana necessita de tempo e energia materializados no trabalho do cuidado, principalmente em períodos como a infância e a velhice, ou em decorrência de enfermidades. Assim, depender do cuidado é uma condição inevitável em determinados momentos da vida, devido às fragilidades inerentes à dependência do cuidado.

Diante disso, a imbricação de marcadores como gênero, raça e classe desvenda a vulnerabilidade das pessoas que estão envolvidas nesta atividade, sejam elas cuidadoras ou a quem o cuidado se direciona. Isso se reflete no acesso a este tipo de trabalho: no Brasil, são os homens brancos de classe alta a quem o cuidado mais se direciona, ao passo que, entre as pessoas que cuidam, as mulheres negras de camadas mais baixas ocupam a primeira posição (BIROLI, 2018). É nesse cenário de uma divisão do trabalho hierarquizada e baseada no gênero, mas com agravamentos importantes relacionados à raça e à classe, que a desvalorização atinge tanto as pessoas que cuidam como aquelas que são cuidadas, além de tornar a própria atividade de cuidar um trabalho invisível (HERRERO, 2013).

A ocultação do trabalho do cuidado como essencial à reprodução da vida e também às atividades produtivas teve como pilar a organização familiar nuclear (HERRERO, 2013). Tal organização familiar foi predominante no Brasil até meados da década de 1970, e tinha como base o trabalho produtivo do homem chefe de família e a responsabilização da muIher pelo trabalho reprodutivo (BILAC, 2014). Contudo, a partir dessa década houve transformações importantes que modificaram tanto as relações familiares como as dinâmicas 
econômicas. Segundo Bilac (2014), três elementos foram fundamentais nesse processo: a expansão do trabalho feminino na indústria, a organização política da classe operária e a "modernização" do consumo. Tais transformações, contudo, não foram acompanhadas por políticas articuladas de bem-estar social. Ao contrário, a esfera reprodutiva do trabalho permaneceu a cargo das famílias e, frequentemente, das mulheres (BILAC, 2014).

A partir dessas transformações, foi necessário conciliar a inserção mais intensa das mulheres no mercado de trabalho com as atividades domésticas, de forma que o cuidado com as crianças, idosos e enfermos passou a demandar novas soluções (PASSOS; WALTENBERG, 2016). Para as mulheres das camadas mais altas, uma resposta foi a contratação de terceiros para realizar esta função - geralmente outras mulheres, porém mais pobres, migrantes e com menor qualificação (HIRATA, 2014). Na falta de oferta de serviços públicos de cuidado, as mulheres das classes mais baixas, que não poderiam arcar com tais contratações, viram-se obrigadas a conciliar o trabalho remunerado com a dedicação aos seus familiares (BIROLI, 2018). Para elas, a solução é procurar ocupações cujas jornadas de trabalho sejam mais flexíveis ou menores. Tais ocupações, no entanto, apresentam pior remuneração e são menos estáveis (PASSOS; WALTENBERG, 2016).

Hirata e Kergoat (2007) expõem que as soluções possíveis tanto para as mulheres mais ricas quanto para as mais pobres reforçam a divisão sexual do trabalho, apresentando dois modelos de execução de tarefas domésticas. 0 primeiro deles é o "modelo de conciliação", no qual se enquadram as mulheres das classes mais baixas, que visa ao equilíbrio entre trabalho produtivo e trabalho doméstico. No entanto, a conciliação destas duas esferas é restrita quase exclusivamente às mulheres, uma vez que não se espera que a rotina de trabalho remunerado dos homens se adapte às atividades domésticas e do cuidado. Já o "modelo de delegação", presente entre as pessoas das classes mais altas, diz respeito à exteriorização do trabalho doméstico a partir da contratação de outras mulheres para realizarem esta função, de forma que não seja necessário "conciliar” diferentes esferas. Segundo Hirata e Kergoat (2007, p. 607), mesmo no modelo de delegação, está implícita uma assimetria nas responsabilidades domésticas e familiares:

Mesmo que exista delegação, um de seus limites está na própria estrutura do trabalho doméstico e familiar: a gestão do conjunto do trabalho delegado é sempre da competência daquelas que delegam.

Além do modelo de delegação do trabalho reprodutivo à empregada doméstica e da conciliação entre trabalho remunerado e trabalho reprodutivo, outra forma de delegar esta atividade foi buscar ajuda na comunidade ou na família: vizinhas, "mães-crecheiras", filhas mais velhas, avós e tias também fazem parte da rede de cuidados que apoia as mulheres ocupadas fora de casa (BILAC, 2014).

Tais modelos de conciliação e de delegação, assim, mostram-se ineficazes para superar o que se chama hoje de crise do cuidado, a qual é caracterizada pelo aumento da necessidade de cuidados e uma concomitante queda na provisão desses trabalhos (GRECCO, 2017). 
O aumento da demanda está relacionado ao envelhecimento da população, ao passo que a redução na oferta tem como razões a queda na taxa de fecundidade, a ausência do Estado no suprimento dessas necessidades e o desinteresse do mercado em assumir alguma responsabilidade no tema. Dessa forma, ocorre o que Grecco (2017) analisa como uma desestabilização do padrão de separação entre as esferas pública e privada, ao mesmo tempo que se aprofundam as desigualdades fundadas nessa divisão - como é o caso das desigualdades de gênero, raça e classe.

\section{Transferências de renda e o trabalho doméstico e do cuidado: o caso do Bolsa Família}

Também foi na década de 1970 - período de transformações na economia brasileira, bem como nas estruturas familiares - que teve início o debate sobre a transferência de renda no Brasil como forma de combate à pobreza, influenciado pela ideia do imposto negativo de Milton Friedman (FONSECA, 2001). A pobreza é condição relevante quando se deseja analisar o trabalho do cuidado sob o prisma dos estudos de gênero, uma vez que as vulnerabilidades associadas a esta atividade evidenciam que as desigualdades de gênero devem ser analisadas em conjunto a outros elementos, tais como classe e raça. Além disso, as políticas públicas que têm como objetivo aliviar as condições de pobreza frequentemente são focalizadas nas mulheres dos domicílios (FARAH, 2004). No caso brasileiro, as famílias chefiadas por mulheres negras estão em situação ainda mais vulnerável (MARIANO; CARLOTO, 2011).

Os programas de transferência de renda, como o Bolsa Família, estão inseridos nessa agenda de combate à vulnerabilidade social. No caso do PBF, as famílias recebem transferências financeiras mensais e, em contrapartida, devem cumprir determinadas condicionalidades nas áreas da saúde e da educação. 0 benefício é pago preferencialmente à mãe da família, ou outra mulher que exerça função de chefe do domicílio (BRASIL, 2004, 2020b).

É sobre a preferência pela titularidade feminina e o cumprimento das condicionalidades que as discussões sobre as desigualdades de gênero se concentram. A escolha por direcionar os benefícios às mulheres tem como objetivo potencializar os efeitos da política pública no alívio das condições de pobreza (FARAH, 2004; MARIANO; CARLOTO, 2009). Tais efeitos não estão relacionados somente ao recebimento do benefício, mas também ao cumprimento das contrapartidas exigidas para que as famílias permaneçam no programa (MEDEIROS; BRITTO; SOARES, 2007). Essas exigências buscam interromper o ciclo intergeracional da pobreza (MEDEIROS; BRITTO; SOARES, 2007), incentivando os participantes a realizarem acompanhamentos de saúde regulares (principalmente para gestantes, nutrizes e crianças de até seis anos) e desincentivando o trabalho infantil, na medida em que existem exigências mínimas de presença escolar para crianças e adolescentes entre 6 e 17 anos (BRASIL, 2020b). 
A opção por direcionar as transferências financeiras às mães tem duas principais justificativas. A primeira, já citada, diz respeito à potencialização dos efeitos da política pública (FARAH, 2004). A preferência pela titularidade feminina decorre tanto da existência prévia de tal requisito nos programas unificados pelo PBF, quanto pelo fato de que a inscrição das famílias no Cadastro Único exige a indicação de um responsável familiar, frequentemente a mãe do domicílio (BARTHOLO; PASSOS; FONTOURA, 2019). A perspectiva do programa é de que as mulheres aloquem os recursos de maneira mais eficiente e justa do que os homens, trazendo maior bem-estar à família (MARIANO; CARLOTO, 2009). Tal escolha, embora conceitual, tem respaldo em análises empíricas sobre as mudanças na composição dos gastos das famílias quando se destina o benefício às mulheres, que passam a consumir mais alimentos, roupas, remédios e materiais escolares (BARTHOLO; PASSOS; FONTOURA, 2019).

A segunda justificativa está relacionada ao enfrentamento e à redução das desigualdades de gênero - embora, no caso do PBF, essa justificativa não esteja evidente na lei que regulamenta a política, mas está presente em alguns informativos sobre o programa. 0 argumento é que as mulheres, quando têm acesso ao benefício, podem apresentar ganhos de autonomia e de cidadania (REGO; PINZANI, 2014), têm sua autoridade afirmada dentro de casa (SUÁREZ; LIBARDONI, 2007) e têm os trade-offs entre aceitar ou não determinados empregos alterados (SANTOS, 2014). A autonomia financeira diz respeito à possibilidade de fazer as compras sem recorrer ao companheiro, enquanto a autoridade da mulher no domicílio está relacionada ao aumento do seu poder de barganha, ou seja, à melhora nas condições de negociação dentro de casa e à capacidade de ter suas preferências consideradas nas decisões sobre as despesas domésticas. Ademais, a participação no programa amplia as possibilidades de escolha das beneficiárias, uma vez que podem recusar empregos vexatórios, insalubres e de baixa remuneração (REGO; PINZANI, 2014; SANTOS, 2014).

No entanto, o desenho do programa pode implicar efeitos não esperados pela política. Bartholo, Passos e Fontoura $(2019$, p. 5) indicam três eixos de críticas ao desenho do programa feitos por autoras feministas, sendo eles: “i) a definição da titularidade feminina do benefício; ii) a exigência de condicionalidades; e iii) sua incapacidade para ampliar as possibilidades de escolhas individuais femininas".

Um primeiro ponto de atenção é a própria focalização da política num grupo específico: as mulheres. Para Mariano e Carloto (2011), a mulher é escolhida como representante da família, numa designação de papéis que reforçam os tradicionais produzidos e reproduzidos pela divisão sexual do trabalho. Dessa forma, as mulheres, mais uma vez, têm o papel de realizar a ponte entre a família (esfera privada) e o Estado (esfera pública), a partir de atividades relacionadas à maternidade ou à maternagem - ou seja, ocupações que remetem ao trabalho doméstico e do cuidado. Ao designar tais responsabilidades às titulares do benefício, o PBF não incentiva a superação das desigualdades de gênero, mas acaba por reforçar os papéis sociais tradicionais (MARIANO; CARLOTO, 2009, 2011). Ademais, Bartholo, Passos e Fontoura (2019) argumentam que o viés pró-criança do PBF é 
evidente na seleção das famílias elegíveis ao recebimento das transferências: as famílias em condição de pobreza - aquelas cuja renda mensal per capita esteja entre $\mathrm{R} \$ 89,00 \mathrm{e}$ $\mathrm{R} \$ 178,00$ - devem ter crianças e adolescentes até 17 anos em sua composição para que se enquadrem nos critérios do Programa. Já as famílias em condição de extrema pobreza - com renda mensal per capita de até $R$ \$ 89,00 - são elegíveis independentemente da composição (BARTHOLO; PASSOS; FONTOURA, 2019; BRASIL, 2020b).

Nesse sentido, a crítica feminista ao PBF argumenta que a titularidade feminina é uma forma de "instrumentalizar" as mulheres a fim de cumprir uma agenda de combate à pobreza, aproveitando-se de um lugar social percebido como "natural" e desconsiderando as possíveis consequências negativas para as relações de gênero (MARIANO; CARLOTO, 2011; SILVEIRA, 2004). Os benefícios, assim, são pagos à mulher como forma de suprir suas necessidades enquanto pessoas pobres, não em relação à situação de subordinação feminina (MARIANO; CARLOTO, 2009). Oferecer uma transferência financeira às famílias e deixá-la a cargo das mulheres seria um "atalho", na medida em que não provoca mudanças estruturais nas desigualdades de gênero, mas alivia certas tensões imediatas, ao mesmo tempo que se aproveita dos papéis sociais construídos pela divisão sexual do trabalho (SILVEIRA, 2004).

O reforço desses papéis tradicionais também aconteceria, segundo tal argumentação, pelo aumento da carga de trabalho doméstico e do cuidado a que as beneficiárias estariam submetidas (PASSOS, 2015). A sobrecarga, segundo tais críticas, está relacionada à responsabilização da mulher, na condição de titular do benefício, pelo cumprimento das contrapartidas exigidas pelo programa. A fim de manter as transferências, as crianças com até seis anos devem estar com a imunização em dia e fazer acompanhamentos de saúde regulares. Além disso, crianças e adolescentes entre 6 e 17 anos devem estar matriculados na escola e cumprir taxas mínimas de frequência. Gestantes e nutrizes também devem realizar acompanhamentos pré e pós-natais (BRASIL, 2004, 2020b). Todas essas condições exigem, de alguma forma, o exercício do papel de mãe e de cuidadora.

O terceiro conjunto de críticas apontado por Bartholo, Passos e Fontoura (2019) refere-se a uma suposta incapacidade do programa em proporcionar maiores possibilidades de escolhas para as beneficiárias, uma vez que não oferece suporte para que elas se dediquem ao trabalho produtivo. Assim, a participação no PBF reforçaria a ocupação dessa posição de mãe e cuidadora, ao mesmo tempo que afastaria essas mulheres do mercado de trabalho, condição agravada, ainda, pela insuficiência na oferta de equipamentos públicos, como creches e escolas para crianças de até três anos (BARTHOLO; PASSOS; FONTOURA, 2019).

Embora esta seja uma preocupação relevante do ponto de vista feminista, as autoras alertam para uma ruptura nos papéis sociais a partir da titularidade feminina: ao trazer à família uma renda regular, as mulheres assumem uma tarefa tradicional e majoritariamente masculina. A contribuição feminina à renda familiar é, assim, uma melhora nas condições de vida das mulheres, conforme também relatam Santos (2014) e Rego e Pinzani (2014). É por meio dessa renda que muitas mulheres viram a possibilidade de melhorar o poder 
de negociação dentro de casa, ter suas preferências consideradas com relação aos gastos da família e até mesmo puderam romper relacionamentos infelizes e violentos (SANTOS, 2014; REGO; PINZANI, 2014). Para além da contribuição feminina à renda total da família, Bartholo, Passos e Fontoura (2019) reconhecem a necessidade de maior provisão de equipamentos públicos que deem suporte às famílias e ofereçam maiores possibilidades de escolhas às mulheres, elementos que escapam aos instrumentos e objetivos do PBF.

Desses conjuntos de críticas, o que fica evidente é que os efeitos do programa sobre as relações de gênero ainda são ambíguos: ao mesmo tempo que permitem às mulheres tomarem decisões, a titularidade feminina se utiliza da construção dos gêneros para potencializar seus resultados sobre a superação da pobreza. Além disso, as atividades realizadas pelas beneficiárias e a forma como elas usam o seu tempo trazem indícios de reforço desses papéis tradicionais ligados à maternidade, à maternagem e ao cuidado.

Para Passos (2015), o aumento do tempo dedicado à casa e à família, assim, seria evidência de que o programa não ajuda a romper com as desigualdades de gênero nas relações familiares, mas que se baseia nessas assimetrias como forma de potencializar seus efeitos sobre as condições de pobreza. A autora comparou o uso do tempo em atividades remuneradas e não remuneradas para indivíduos beneficiários e não beneficiários do PBF. Quando contrapostas as horas dedicadas ao trabalho doméstico realizado por participantes e não participantes do programa, a autora observa que o primeiro grupo dedica mais tempo do que o segundo. Entre os homens participantes, aqueles que não são beneficiários da política despendem mais horas de trabalho doméstico do que aqueles que recebem o benefício (PASSOS, 2015).

Em se tratando do trabalho do cuidado, existe ainda o desafio de separá-lo das demais atividades realizadas no universo doméstico. 0 trabalho do cuidado é percebido como uma extensão do trabalho doméstico, de forma que as pesquisas não isolam de forma ideal estas atividades. Isto dificulta a mensuração do trabalho do cuidado desintegrado do trabalho doméstico geral e, por consequência, limita as abordagens das pesquisas que se debruçam sobre o tema. No caso das participantes do PBF, tal limitação se torna ainda mais evidente, na medida em que as pesquisas censitárias não têm como objetivo uma amostra representativa desta população, o que pode gerar vieses de representatividade e de captação (SOUZA, 2013).

\section{Materiais e métodos}

A fim de analisar de que forma beneficiárias e não beneficiárias do PBF dedicam seu tempo aos trabalhos doméstico e do cuidado, o presente estudo utiliza a PNAD Contínua 2019, especificamente a entrevista realizada na quinta visita. A PNAD Contínua tem a vantagem de possuir uma amostra robusta da população brasileira, apresentando um desenho amostral complexo, que considera os pesos relativos a cada região, município, estrato, domicílio ou indivíduo. A PNAD Contínua conta com perguntas sobre realização 
de trabalho remunerado e não remunerado, além de dispor de um bloco sobre tempo dedicado ao trabalho doméstico e do cuidado. Além disso, os microdados da pesquisa estão disponíveis para acesso do público geral.

Uma limitação importante na utilização da PNAD Contínua para analisar dados de beneficiários de programas sociais é o desenho amostral, que não busca ser representativo do público-alvo desses programas, mas sim de toda a população. Dessa forma, é importante salientar que a análise da PNAD Contínua para os grupos de beneficiários e não beneficiários permite uma investigação descritiva, que deve ser apresentada com cautela. Ainda assim, a PNAD Contínua realizada em 2019 conta com a pergunta "Recebeu rendimentos de Programa Bolsa Família?”, questão que foi fundamental para estabelecer o grupo de beneficiários analisado no estudo.

Tais análises são possíveis, também, em função das recentes mudanças no questionário. Na PNAD anual, que era realizada até 2015, os afazeres relacionados ao trabalho do cuidado estavam implícitos em uma única pergunta sobre cuidados de filhos ou outros residentes. Já na PNAD Contínua, o trabalho do cuidado passou a ser investigado com questões mais específicas, que detalham algumas atividades, tais como auxiliar em tarefas escolares, colocar para dormir, dar banho e acompanhar a criança até a escola, por exemplo (SOARES, 2018).

Este avanço metodológico contribuiu para os estudos de gênero por ampliar a percepção do que se entende por trabalho doméstico e do cuidado, conforme Soares (2018) expõe. Assim, é possível que homens que executam certas tarefas antes respondessem que não realizam qualquer atividade dentro de casa. Seja por entenderem que o trabalho doméstico é "coisa de mulher", seja por considerar que prestavam apenas uma "ajuda", um maior detalhamento de atividades teve como resultado um maior percentual de homens que relataram realizar trabalho doméstico e do cuidado (SOARES, 2018). Ainda assim, algumas limitações da PNAD Contínua constituem desafios para a área dos estudos de gênero. Uma delas é a questão sobre o uso do tempo, uma vez que os respondentes declaram apenas o tempo total dedicado ao trabalho doméstico e do cuidado, dificultando a mensuração do tempo empregado em cada atividade isoladamente (SOARES, 2018).

Os dados utilizados foram extraídos diretamente do site do Instituto Brasileiro de Geografia e Estatística (IBGE) pelo software R, com o pacote específico disponibilizado pelo instituto para trabalhar com a PNAD Contínua, já considerando os pesos do desenho amostral complexo da pesquisa. Assim, foram extraídas informações de dois grupos. 0 primeiro deles é o grupo de beneficiários do PBF, que concentra aqueles que responderam receber o benefício, totalizando 9.163 .937 pessoas ( 8.344 .682 mulheres e 819.255 homens). Para fins de comparação, este trabalho estabeleceu o critério de renda para desenhar o grupo de não beneficiários, considerando a renda per capita máxima de $\mathrm{R} \$ 178,00$ para aqueles que responderam não receber o benefício, num total de 16.141.933 indivíduos (7.118.405 mulheres e 9.023 .528 homens). Tais observações referem-se à expansão da amostra da PNAD Contínua de acordo com os pesos amostrais. 


\section{Resultados}

Os primeiros resultados extraídos demonstram que a divisão sexual do trabalho não está desvinculada das relações de classe e de raça, uma vez que são as mulheres pretas da menor faixa salarial as que mais se dedicam ao trabalho doméstico e do cuidado (BIROLI, 2018). Ao observar a média de horas semanais empregadas no trabalho doméstico e do cuidado segundo as faixas salariais, é possível compreender que a classe é o que diferencia se a família ou o indivíduo seguirão pelo "modelo de delegação" ou pelo "modelo de conciliação". As Tabelas 1 e 2 mostram que tanto o gênero quanto a raça e a faixa salarial têm influência no tempo dedicado às atividades domésticas.

TABELA 1

Horas semanais dedicadas por mulheres ao trabalho doméstico, por raça, segundo faixas salariais Brasil - 2019

\begin{tabular}{lcrccc}
\hline \multicolumn{1}{c}{ Faixas salariais } & Brancas & Pretas & Pardas & Indígenas & Amarelas \\
\hline Até 1/4 salário mínimo & 23,9 & 24,5 & 24,1 & 22,5 & 24,3 \\
Mais de 1/4 até 1/2 salário mínimo & 24,2 & 24 & 24,1 & 21,8 & 22,5 \\
Mais de 1/2 até 1 salário mínimo & 22,2 & 21,8 & 22,1 & 23,8 & 24,4 \\
Mais de 1 até 2 salários mínimos & 20,7 & 20,1 & 20,4 & 22,5 & 18,9 \\
Mais de 2 até 3 salários mínimos & 18,8 & 18,7 & 19,4 & 21,2 & 18,8 \\
Mais de 3 até 5 salários mínimos & 18 & 17 & 17,7 & 21,3 & 14,3 \\
Mais de 5 salários mínimos & 15,9 & 16,1 & 16,4 & 10,6 & 15,9 \\
\hline
\end{tabular}

Fonte: IBGE. PNAD Contínua 2019.

TABELA 2

Horas semanais dedicadas por homens ao trabalho doméstico, por raça, segundo faixas salariais Brasil - 2019

\begin{tabular}{lccccc}
\hline \multicolumn{1}{c}{ Faixas salariais } & Brancos & Pretos & Pardos & Indígenas & Amarelos \\
\hline Até 1/4 salário mínimo & 11,6 & 11,3 & 10,9 & 10,4 & 11,3 \\
Mais de 1/4 até 1/2 salário mínimo & 11,1 & 10,7 & 10,8 & 11 & 11,6 \\
Mais de 1/2 até 1 salário mínimo & 11,3 & 11,3 & 10,9 & 12,8 & 12,6 \\
Mais de 1 até 2 salários mínimos & 10,9 & 11,5 & 11 & 8,62 & 13,7 \\
Mais de 2 até 3 salários mínimos & 11 & 11,6 & 11,3 & 15,6 & 11,5 \\
Mais de 3 até 5 salários mínimos & 10,6 & 10,6 & 11,5 & 12,9 & 11,1 \\
Mais de 5 salários mínimos & 9,78 & 11 & 10,1 & 11,2 & 10,7 \\
\hline
\end{tabular}

Fonte: IBGE. PNAD Contínua 2019.

Quanto maior a faixa salarial, menos horas são dedicadas ao trabalho doméstico, independentemente do gênero ou da raça. Contudo, a diferença no tempo dedicado a essa atividade é maior para as mulheres, o que sugere que a renda seja determinante na possibilidade de delegar os serviços domésticos e do cuidado a outra pessoa, como empregadas domésticas, diaristas, babás ou enfermeiras - o que evidencia o "modelo de delegação" elaborado por Hirata e Kergoat (2007), segundo o qual mulheres das classes mais altas podem delegar essas funções às mulheres das camadas mais baixas, em especial as negras. Mesmo assim, nas faixas salariais mais altas, as mulheres ainda precisam, em 
certa medida, conciliar seus demais compromissos com o trabalho reprodutivo. Para os homens, a faixa de renda parece ter bem menos influência na conciliação ou delegação de tarefas domésticas e do cuidado.

Para as faixas de renda mais baixas, em que estão inseridos os grupos analisados neste trabalho, as mulheres chegam a realizar mais do que o dobro de horas de trabalho doméstico do que os homens. Assim, a fim de investigar de que forma a participação familiar no PBF pode ter relação com o reforço dos papéis tradicionais de gênero, foram comparados os grupos de famílias beneficiárias e não beneficiárias quanto ao uso do tempo dedicado a tais atividades.

Os grupos comparados não apresentam diferenças significativas no que diz respeito à média de pessoas nos domicílios, tipos de família e situação dos domicílios. Porém, com relação à composição familiar, alguns pontos se tornam relevantes. Em primeiro lugar, entre as famílias beneficiárias, $87,33 \%$ das pessoas de referência são mulheres, provavelmente pela preferência já citada do Cadastro Único e pela condição de participar do PBF, cuja titularidade é feminina na maior parte dos casos (BRASIL, 2004). Já na condição de cônjuge ou companheira do sexo oposto, as mulheres representam mais de $98 \%$ do total para o grupo de famílias beneficiárias, como se pode observar na Tabela 3. Entre as famílias não beneficiárias, os homens correspondem a $66,17 \%$ das pessoas de referência no domicílio e são 52,7\% dos cônjuges ou companheiros do sexo oposto, conforme mostra a Tabela 4.

TABELA 3

Condição no domicílio para famílias beneficiárias do PBF, por sexo

Brasil - 2019

\begin{tabular}{lll}
\hline \multicolumn{1}{c}{ Condição no domicílio } & \multicolumn{1}{c}{ Sexo } & \multicolumn{1}{c}{$\%$} \\
\hline Pessoa responsável pelo domićlio & Homem & 12,67 \\
Pessoa responsável pelo domicílio & Mulher & 87,33 \\
Cônjuge ou companheiro(a) de sexo diferente & Homem & 1,90 \\
Cônjuge ou companheiro(a) de sexo diferente & Mulher & 98,10 \\
\hline Fonte: IBGE. PNAD Contínua 2019. &
\end{tabular}

TABELA 4

Condição no domicílio para famílias não beneficiárias do PBF, por sexo Brasil - 2019

\begin{tabular}{lcc}
\hline \multicolumn{1}{c}{ Condição no domicílio } & Sexo & $\%$ \\
\hline Pessoa responsável pelo domicílio & Homem & 66,17 \\
Pessoa responsável pelo domicílio & Mulher & 33,83 \\
Cônjuge ou companheiro(a) de sexo diferente & Homem & 52,70 \\
Cônjuge ou companheiro(a) de sexo diferente & Mulher & 47,30 \\
\hline Fonte: IBGE. PNAD Contínua 2019. & &
\end{tabular}

Outras diferenças se tornam evidentes no que diz respeito à presença de cônjuge, conforme as Tabelas 5 e 6 revelam. Entre as famílias beneficiárias do PBF, as mulheres responsáveis pelo domicílio não têm cônjuge em $98 \%$ dos casos. Já entre as não beneficiárias, o percentual de mulheres nessa condição é de $74 \%$. 0 alto percentual 
encontrado na exploração da PNAD Contínua 2019 contrasta com pesquisas como as conduzidas por Suárez e Libardoni (2007) e Alves e Cavenaghi (2009), por exemplo, ambas realizadas com foco em localidades específicas e não com base numa pesquisa amostral como a PNAD Contínua. Na primeira pesquisa, o cônjuge está ausente em $46 \%$ das famílias beneficiárias e, na segunda, em 51\% dos domicílios (ALVES; CAVENAGHI, 2009; SUÁREZ, LIBARDONI, 2007).

TABELA 5

Mulheres beneficiárias do PBF responsáveis pelo domicílio, segundo condição de conjugalidade Brasil - 2019

\begin{tabular}{lrr}
\hline \multicolumn{1}{c}{ Condição de conjugalidade } & N & \% \\
\hline Total de mulheres beneficiárias que são pessoas de referência & 3.849 .739 & 100,0 \\
Sem cônjuge & 3.775 .437 & 98,07 \\
Com cônjuge & 74.302 & 1,93 \\
\hline
\end{tabular}

Fonte: IBGE. PNAD Contínua 2019.

TABELA 6

Mulheres não beneficiárias do PBF responsáveis pelo domicílio, segundo condição de conjugalidade Brasil - 2019

\begin{tabular}{lrr}
\hline \multicolumn{1}{c}{ Condição de conjugalidade } & N & \% \\
\hline Total de mulheres não beneficiárias que são pessoas de referência & 1.359 .905 & 100,0 \\
Com cônjuge & 356.433 & 26,21 \\
Sem cônjuge & 1.003 .471 & 73,79 \\
\hline
\end{tabular}

Fonte: IBGE. PNAD Contínua 2019.

Dessa forma, é necessário ter certa cautela para analisar percentuais de mulheres beneficiárias que possuem e não possuem cônjuge segundo os dados da PNAD Contínua. Conforme Bartholo e Araújo (2008) alertam, a base de dados mais adequada para discutir arranjos familiares para beneficiários de programas sociais é o Cadastro Único, e não a PNAD, uma vez que é do objetivo do primeiro conter as informações referentes às famílias com baixa renda no Brasil. 0 Cadastro Único constitui um registro administrativo contínuo, enquanto a PNAD é uma pesquisa amostral. As próprias definições de "família" diferem entre eles, de forma que os dados extraídos da PNAD sobre arranjos familiares podem divergir, em certa medida, dos estimados pelo Cadastro Único (BARTHOLO; ARAÚJO, 2008) - o que está, também, relacionado aos limites no uso da PNAD Contínua para analisar a população de beneficiários de programas sociais (SOUZA, 2013).

De qualquer forma, é nítido o peso sobre a mulher adulta na responsabilidade do domicílio, com ou sem cônjuge, em especial quando se comparam as famílias que recebem e as que não recebem o PBF. 0 número de mulheres beneficiárias é substancialmente maior do que o de homens que se declaram cônjuges do sexo oposto ou pessoas de referência. Essa diferença entre o número de homens e mulheres nas famílias beneficiárias precisa ser mais bem investigada, no entanto, autoras como Santos (2014) 
deixam pistas sobre as possíveis explicações. Uma delas diz respeito à possibilidade de mulheres titulares superarem relacionamentos marcados por violência, uma vez que o recebimento do benefício aumentaria sua independência financeira e autonomia (SANTOS, 2014).

Com relação às horas semanais dedicadas ao trabalho doméstico e do cuidado, as mulheres amarelas beneficiárias do PBF aparecem com o maior número de horas despendidas, seguidas pelas pardas e indígenas, também beneficiárias, conforme mostra a Tabela 7. Entre os homens, os beneficiários do Bolsa Família autodeclarados amarelos são os que dedicam maior tempo a tais atividades, enquanto os indígenas beneficiários são os que gastam menos horas, seguidos pelos indígenas não beneficiários e pardos não beneficiários.

TABELA 7

Média de horas semanais dedicadas ao trabalho doméstico e do cuidado, por sexo e condição de beneficiários do PBF, segundo cor/raça

Brasil - 2019

\begin{tabular}{lccccc}
\hline & \multicolumn{2}{c}{ Beneficiários do PBF } & & \multicolumn{2}{c}{ Não beneficiários do PBF } \\
\cline { 2 - 3 } \cline { 5 - 6 } \multicolumn{1}{c}{ Cor/raça } & Homens & Mulheres & & Homens & Mulheres \\
\hline Branca & 11,80 & 26,95 & & 11,96 & 22,22 \\
Preta & 12,32 & 26,90 & & 11,40 & 21,27 \\
Amarela & 15,34 & 28,51 & & 11,95 & 22,76 \\
Parda & 13,08 & 27,84 & & 11,06 & 21,42 \\
Indígena & 10,45 & 27,12 & & 10,57 & 18,92 \\
\hline
\end{tabular}

Fonte: IBGE. PNAD Contínua 2019.

Quando comparamos os grupos em relação à condição no domicílio, é possível observar que, para ambos, as mulheres dedicam mais tempo ao trabalho doméstico e do cuidado do que os homens, tanto em condição de cônjuge do sexo oposto quanto na situação de pessoa de referência. Nesse aspecto, a condição no domicílio parece ter mais influência nas horas dedicadas ao trabalho doméstico do que o recebimento ou não do benefício, embora a média de horas ainda seja maior para o grupo de beneficiárias. Para os dois grupos, as mulheres cônjuges dedicam, em média, mais horas do que aquelas que são pessoas de referência. Ao mesmo tempo, para os homens, a condição no domicílio tem pouca influência nas horas despendidas no trabalho doméstico e do cuidado para os dois grupos analisados. A maior diferença foi encontrada para os homens autodeclarados pretos: quando cônjuges do sexo oposto, os não beneficiários dedicam, em média, seis horas a mais nessas atividades do que os beneficiários. As informações coletadas sobre o tempo gasto no trabalho doméstico por condição no domicílio estão na Tabela 8. 
TABELA 8

Horas semanais dedicadas ao trabalho doméstico e do cuidado por cor/raça, segundo sexo, condição de beneficiário do PBF e condição no domicílio

Brasil - 2019

\begin{tabular}{|c|c|c|c|c|c|}
\hline Variáveis & Amarela & Branca & Indígena & Parda & Preta \\
\hline \multicolumn{6}{|l|}{ Mulheres beneficiárias } \\
\hline Pessoa responsável pelo domicílio & 26,72 & 25,77 & 27,46 & 27,34 & 26,02 \\
\hline Cônjuge ou companheiro(a) de sexo diferente & 34,08 & 29,06 & 27,71 & 28,88 & 27,93 \\
\hline \multicolumn{6}{|l|}{ Mulheres não beneficiárias } \\
\hline Pessoa responsável pelo domicílio & 24,04 & 25,83 & 27,51 & 25,74 & 24,07 \\
\hline Cônjuge ou companheiro(a) de sexo diferente & 30,95 & 27,42 & 21,21 & 26,38 & 28,88 \\
\hline \multicolumn{6}{|l|}{ Homens beneficiários } \\
\hline Pessoa responsável pelo domicílio & 15,54 & 11,43 & 11,38 & 13,56 & 13,42 \\
\hline Cônjuge ou companheiro(a) de sexo diferente & 15,00 & 15,67 & 10,00 & 11,11 & 6,93 \\
\hline \multicolumn{6}{|l|}{ Homens não beneficiários } \\
\hline Pessoa responsável pelo domicílio & 12,56 & 12,88 & 11,64 & 12,35 & 11,60 \\
\hline Cônjuge ou companheiro(a) de sexo diferente & 13,76 & 12,55 & 9,97 & 11,49 & 13,01 \\
\hline
\end{tabular}

Fonte: IBGE. PNAD Contínua 2019.

A condição no domicílio, assim, aponta para desdobramentos importantes. Apesar de mulheres beneficiárias serem a maioria das pessoas de referência, isso não as isenta da responsabilização desproporcional pelo trabalho doméstico e do cuidado. Isto favorece um reforço dos papéis de gênero e não contribui para o processo de individualização das beneficiárias (PASSOS, 2015). Ao se aproveitar dessas construções sociais sobre os sexos, inscritas no primeiro conjunto de críticas feministas ao programa e sintetizadas por Bartholo, Passos e Fontoura (2019), o PBF não ajuda a romper a estrutura hierárquica estabelecida que coloca as mulheres em posição de desvantagem, mesmo que elas sejam as pessoas de referência no domicílio. Ao contrário, conforme apontam Mariano e Carloto (2009, 2011), utilizar as mulheres como ponte entre a esfera Estado e família ajuda a enrijecê-la. No entanto, as informações coletadas mostram que a situação é ainda mais desvantajosa para as mulheres cônjuges.

Ainda que a participação no PBF estabeleça que a mulher é a titular preferencial do cartão, o percentual de mulheres beneficiárias que são as pessoas de referência é menor do que o de mulheres titulares, o qual fica em torno de 93\% segundo dados do Cadastro Único. Tal diferença pode estar relacionada aos limites da PNAD Contínua na análise sobre o programa, uma vez que o desenho amostral não busca ser representativo dessa população, o que pode incorrer em vieses de representatividade e de captação (SOUZA, 2013).

Embora a PNAD Contínua não diferencie as horas dedicadas às tarefas domésticas daquelas despendidas ao trabalho do cuidado, as perguntas do questionário permitem verificar quais tipos de atividades são executados no ambiente doméstico. Dessa forma, ocupações domésticas incluem limpar a casa, lavar a louça, lavar, costurar ou consertar roupas, cozinhar, entre outras. Já as atividades que indicam se o indivíduo cuida de algum familiar (residente ou não no mesmo domicílio) englobam auxiliar nos cuidados (vestir, alimentar, dar banho, colocar para dormir), transportar até a escola, auxiliar nas atividades educacionais e fazer companhia. 
É possível, assim, que um participante realize trabalhos domésticos, porém responda que não cuida de algum familiar, residente ou não no mesmo domicílio. Por conta disso, foi investigada a diferença de horas dedicadas ao trabalho doméstico entre os participantes que responderam cuidar de outras pessoas e aqueles que indicaram não realizar tal atividade.

Para os grupos comparados, o trabalho do cuidado representa um aumento significativo nas horas dedicadas às atividades domésticas. Embora homens e mulheres que cuidam de outras pessoas dediquem mais horas do que aqueles que responderam não cuidar (com exceção dos homens brancos e homens pretos beneficiários do PBF), são as mulheres, de maneira geral, que despendem mais tempo. Além disso, as mulheres beneficiárias em condição de cuidadoras gastam mais horas em tais atividades do que todos os outros grupos, destacando-se as indígenas, para as quais a condição de cuidar de algum familiar adiciona, em média, 11 horas de dedicação ao trabalho doméstico e do cuidado. Os Gráficos 1 e 2 sintetizam os resultados.

Para pessoas que realizaram cuidado de crianças com até cinco anos, os dados apontam para uma sobrecarga feminina importante, principalmente para o grupo de famílias beneficiárias do PBF, conforme mostram os Gráficos 3 e 4 . As mulheres beneficiárias autodeclaradas amarelas e pretas são as mais atingidas: o aumento de horas dedicadas ao trabalho doméstico em caso de cuidarem de crianças de até cinco anos é de aproximadamente 11,6 e 8 horas, respectivamente. Nesse caso, é importante salientar que a exigência de matrícula e comparecimento escolar mínimo como condicionalidade do PBF é feita apenas para crianças acima de seis anos (BRASIL, 2020). Assim, não é obrigatório, para permanecer no programa, que as famílias matriculem crianças de até cinco anos em creches e pré-escolas. Além disso, devido à insuficiência na oferta de creches e escolas públicas, em especial para crianças de até três anos (BARTHOLO; PASSOS; FONTOURA, 2019), gera-se um peso desproporcional entre homens e mulheres no cuidado com as crianças menores de seis anos.

\section{GRÁFICO 1}

Horas semanais dedicadas ao trabalho doméstico e do cuidado pelos homens, por cor/raça e situação de beneficiários do PBF, segundo condição de cuidado de outras pessoas

Brasil - 2019

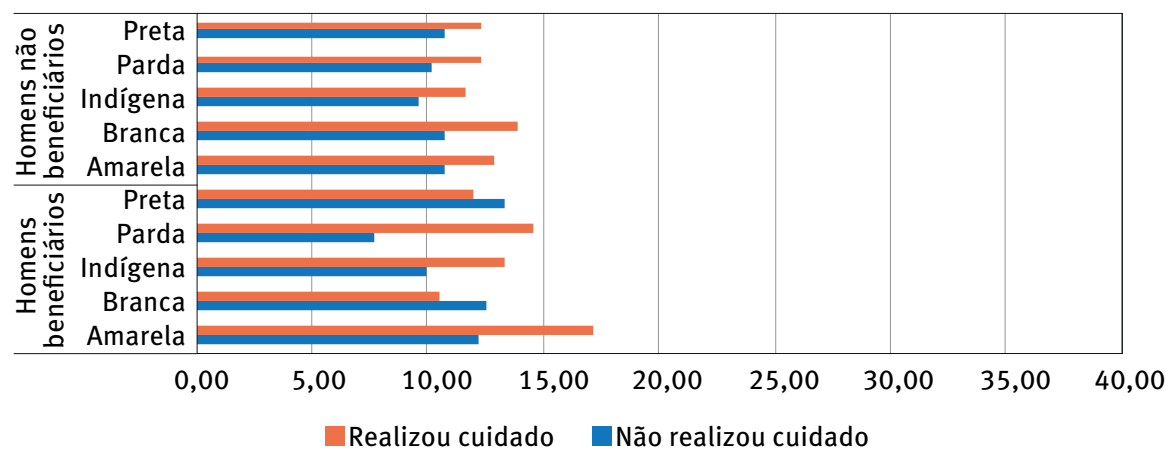

Fonte: IBGE. PNAD Contínua 2019. 


\section{GRÁFICO 2}

Horas semanais dedicadas ao trabalho doméstico e do cuidado pelas mulheres, por cor/raça e situação de beneficiárias do PBF, segundo condição de cuidado de outras pessoas

\section{Brasil - 2019}

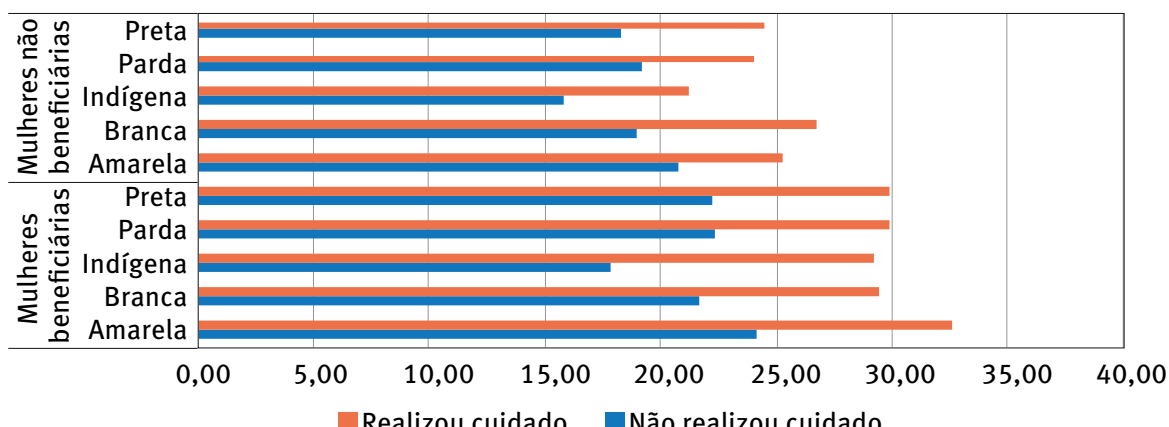

Fonte: IBGE. PNAD Contínua 2019.

GRÁFICO 3

Horas semanais dedicadas ao trabalho doméstico e do cuidado pelas mulheres, por cor/raça e situação de beneficiárias do PBF, segundo condição de cuidado de criança de até cinco anos

Brasil - 2019

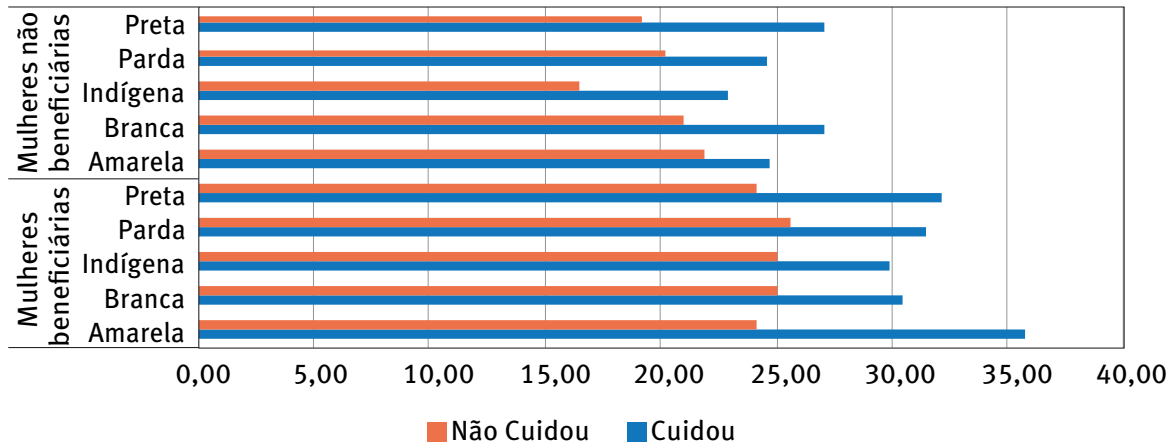

Fonte: IBGE. PNAD Contínua 2019.

GRÁFICO 4

Horas semanais dedicadas ao trabalho doméstico e do cuidado pelos homens, por cor/raça e situação de beneficiários do PBF, segundo condição de cuidado de criança de até cinco anos

Brasil - 2019

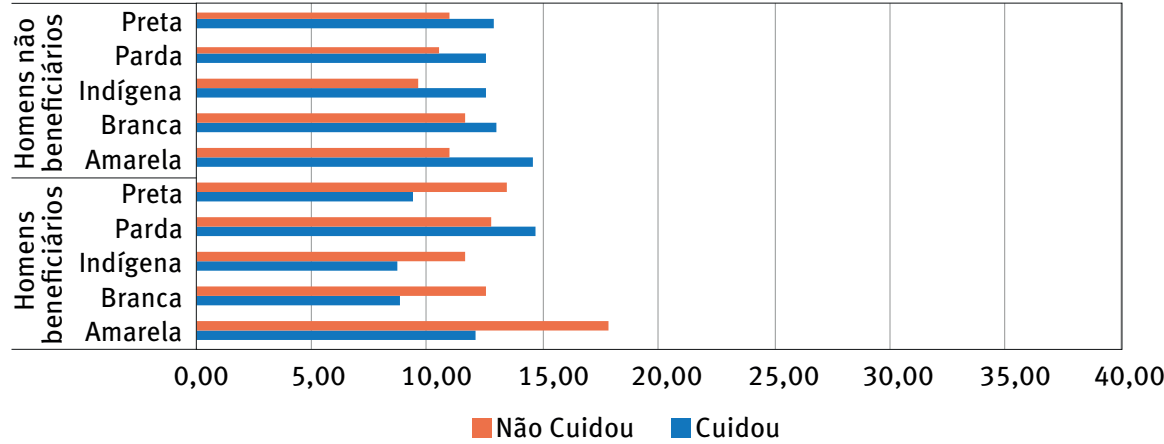

Fonte: IBGE. PNAD Contínua 2019. 
A informação mais relevante é sobre a dedicação masculina ao cuidado das crianças entre os beneficiários do PBF: os homens que responderam cuidar de crianças de até cinco anos dedicam, em média, menos horas ao trabalho doméstico e do cuidado do que aqueles que não cuidam, com exceção dos autodeclarados pardos. Embora o número de horas dedicadas ao trabalho doméstico pelos homens não beneficiários ainda seja inferior ao verificado para as mulheres, para eles, a condição de cuidar de criança de até cinco anos segue a tendência feminina de aumentar o número de horas dedicadas ao trabalho doméstico. Este é um resultado relevante para analisar o reforço dos papéis sociais de gênero para as famílias beneficiárias do PBF. Embora sejam necessárias investigações mais aprofundadas para estabelecer relação de causa e efeito, é interessante observar que a tendência de aumentar o tempo gasto com trabalho do cuidado foi interrompida justamente entre o grupo de homens beneficiários do programa.

\section{Considerações finais}

Neste trabalho, foram analisados os dados disponíveis na PNAD Contínua 2019 para investigar a relação entre a titularidade feminina no PBF e o uso do tempo com trabalho doméstico e do cuidado. Os resultados encontrados revelam que as mulheres beneficiárias do PBF empregam mais horas nas atividades domésticas e do cuidado do que os outros grupos analisados, com destaque para as autodeclaradas amarelas, pardas e indígenas. Além disso, verificou-se que a condição de cuidar de criança de até cinco anos é um fator que eleva a média de horas gastas com tais atividades para todos os grupos, exceto para os homens beneficiários do programa.

Este resultado indica que a presença de crianças de até cinco anos nos domicílios beneficiários tem efeitos diferentes para homens e mulheres, o que abre novas possibilidades de pesquisa para investigar as relações de causa e efeito dessas diferenças. Um elemento a ser indagado é o envolvimento dos homens beneficiários adultos com o trabalho remunerado em comparação às mulheres beneficiárias.

Do cenário apresentado, é possível compreender que o reforço dos papéis sociais de gênero ocorre não somente pela via da sobrecarga feminina com as atividades domésticas e do cuidado, mas em grande medida pela isenção dos homens nessas ocupações. Assim, políticas públicas devem se atentar aos papéis de gênero não como forma de potencializar seus efeitos, mas sim para evitar efeitos ambíguos como o aumento da autonomia financeira somando à sobrecarga com trabalhos domésticos e do cuidado. Aliada a isso, a carência de equipamentos públicos destinados a apoiar as famílias no cuidado com crianças, idosos, pessoas doentes e com deficiências é um fator que pode colaborar para tais rigidezes na distribuição assimétrica de atividades. As transferências de renda não são capazes, sozinhas, de garantir a superação de desigualdades de gênero e raça históricas, mas podem ser aliadas nesse processo. 


\section{Referências}

ALVES, J. E. D.; CAVENAGHI, S. M. Dinâmica demográfica e políticas de transferência de renda: o caso do Programa Bolsa Família no Recife. Revista Latinoamericana de Población, v. 3, n. 4-5, p. 165-188, 2009.

BARTHOLO, L.; ARAÚJO, L. R. C. Em busca das famílias reconstituídas: mapeamento dos arranjos familiares da população brasileira de baixa renda por meio do Cadastro Único de Programas Sociais. In: XVI ENCONTRO NACIONAL DE ESTUDOS POPULACIONAIS. Anais [...]. Caxambu, MG: Abep, 2008.

BARTHOLO, L.; PASSOS, L.; FONTOURA, N. Bolsa Família, autonomia feminina e equidade de gênero: o que indicam as pesquisas nacionais? Cadernos Pagu, n. 55, e195525, 2019.

BRASIL. Presidência da República. Lei n. 10.836, de 9 de janeiro de 2004. Cria o Programa Bolsa Família, altera a Lei n. 10.689, de 13 de junho de 2003, e dá outras providências. Brasília, DF, 2004. Disponivel em: http://www.planalto.gov.br/ccivil_03/_Ato2004-2006/2004/Lei/L10.836. htm. Acesso em: 3 fev. 2021.

BRASIL. Ministério da Cidadania. Bolsa Família atende 14,283 milhões de famílias no mês de junho. Brasília, DF, 2020a. Disponível em: https://www.gov.br/pt-br/noticias/assistenciasocial/2020/07/bolsa-familia-atende-14-283-milhoes-de-familias-no-mes-de-junho. Acesso em: 13 mar. 2021.

BRASIL. Ministério da Cidadania. Bolsa Família: o que é? Brasília, DF, 2020b. Disponível em: https://www.gov.br/cidadania/pt-br/acoes-e-programas/bolsa-familia/o-que-e. Acesso em: 3 fev. 2021.

BILAC, E. D. Trabalho e família: articulações possíveis. Tempo Social - Revista de Sociologia da USP, v. 26, n. 1, p. 129-145, jun. 2014.

BIROLI, F. Gênero e desigualdades: limites da democracia no Brasil. 1. ed. São Paulo: Boitempo, 2018.

CAMARGO, C. F. et al. Perfil socioeconômico dos beneficiários do Programa Bolsa Família: o que o Cadastro Único revela? In: CAMPELO, T.; NERI, M. C. (org.). Bolsa Família: uma década de inclusão e cidadania. Brasília: Ipea, 2013. p. 157-77.

FARAH, M. Gênero e políticas públicas. Estudos Feministas, v. 12, n. 1, p. 47-71, 2004.

FONSECA, A. M. M. Família e política de renda mínima. São Paulo: Cortez, 2001.

GRECCO, F. S. O debate sobre a reprodução social no Brasil nos marcos da "crise do cuidado". In: 41ํㅡㄹ ENCONTRO ANUAL DA ANPOCS. GT 13 - Gênero, Trabalho e Família. Anais [...]. Caxambu: Anpocs, 2017.

HERRERO, Y. Miradas ecofeministas para transitar a un mundo justo y sostenible. Revista de Economía Crítica, n. 16, p. 278-307, segundo semestre 2013.

HIRATA, H. Gênero, raça e classe: interseccionalidade e consubstancialidade das relações sociais. Tempo Social - Revista de Sociologia da USP, v. 26, n. 1, p.61-73, jun. 2014.

HIRATA, H.; KERGOAT, D. Novas configurações da divisão sexual do trabalho. Cadernos de Pesquisa, v. 37, n. 132, p. 595-609, 2007.

IPEA - Instituto de Pesquisa Econômica Aplicada. Retrato das desigualdades de gênero e raça. Brasília, 2017. Disponível em: https://www.ipea.gov.br/retrato/indicadores.html. Acesso em: 5 abr. 2021. 
KERGOAT, D. Divisão sexual do trabalho e relações sociais de sexo. In: KERGOAT, D. et al. (org.). Dicionário crítico do feminismo. São Paulo: Fundação Editora Unesp, 2009.

MARIANO, S. A.; CARLOTO, C. M. Gênero e combate à pobreza: Programa Bolsa Família. Estudos Feministas, v. 17, n. 3, p. 901-908, dez. 2009.

MARIANO, S.; CARLOTO, C. Gênero e combate à pobreza no Programa Bolsa Família. In: BONETTI, A.; ABREU, M. (org.). Faces da desigualdade de gênero e raça no Brasil. Brasília: Ipea, 2011. p. 61-78.

MEDEIROS, M.; BRITTO, T.; SOARES, F. Transferência de renda no Brasil. Novos Estudos - CEBRAP, n. 79, p. 5-21, nov. 2007.

MIGUEL, L. F.; BIROLI, F. Feminismo e política: uma introdução. 1. ed. São Paulo: Boitempo, 2014.

PASSOS, L. Bolsa Família: socializando cuidados e mudando as relações de gênero? 2015. 101 f. Dissertação (Mestrado em Economia) - Centro de Ciências Sociais Aplicadas, Universidade Federal Fluminense, Niterói, 2015.

PASSOS, L.; WALTENBERG, F. D. Bolsa Família e assimetrias de gênero: reforço ou mitigação? Revista Brasileira de Estudos de População, v. 33, n. 3, p. 517-539, set./dez. 2016.

REGO, W. L.; PINZANI, A. Vozes do Bolsa Família: autonomia, dinheiro e cidadania. 2. ed. São Paulo: Editora Unesp, 2014.

SANTOS, G. Gênero, desenvolvimento e Programa Bolsa Família: direitos reprodutivos, trabalho e projetos de vida de mulheres do Coque (Recife/PE). 2014. 226 f. Tese (Doutorado) - Curso de Antropologia, Centro de Filosofia e Ciências Humanas, Universidade Federal de Pernambuco, Recife, 2014.

SILVEIRA, M. L. Políticas públicas de gênero: impasses e desafios para fortalecer a agenda política na perspectiva da igualdade. In: GODINHO, T.; SILVEIRA, M. (org.). Políticas públicas e igualdade de gênero. São Paulo: Prefeitura Municipal, Coordenadoria Especial da Mulher, 2004. p. 65-75.

SOARES, C. As potencialidades da PNAD Contínua para os estudos de gênero: o que há de novo nas análises de afazeres e cuidados? In: XXI ENCONTRO NACIONAL DE ESTUDOS POPULACIONAIS. Anais [...]. Poços de Caldas, MG: Abep, 2018.

SOUZA, P. H. G. F. Uma metodologia para explicar diferenças entre dados administrativos e pesquisas amostrais, com aplicação para o Bolsa Família e o Benefício de Prestação Continuada na PNAD. Revista Brasileira de Estudos de População, v. 30, n. 1, p. 299-315, jan./jun. 2013.

SUÁREZ, M.; LIBARDONI, M. O impacto do Programa Bolsa Família: mudanças e continuidades na condição social das mulheres. In: VAITSMAN, J.; PAES-SOUSA, R. (org.). Avaliação de políticas e programas do MDS - Resultados. Brasília: MDS, Sagi, 2007. v. 2, p. 119-160.

\section{Sobre as autoras}

Jéssica Alves de Lima Germine é mestranda no Programa de Pós-graduação em Ciências Humanas e Sociais na Universidade Federal do ABC (PCHS/UFABC), pós-graduada em Ciência Política pela Escola de Sociologia e Política de São Paulo (FESP-SP) e economista pela Universidade Federal do Paraná (UFPR).

Roberta Guimarães Peres é doutora em Demografia pelo Instituto de Filosofia e Ciências Humanas, da Universidade Estadual de Campinas (IFCH/Unicamp). Professora adjunta da Universidade Federal do ABC, no Bacharelado em Ciências e Humanidades, Bacharelado em Políticas Públicas e Programa de Pós-Graduação em Ciências Humanas e Sociais. 


\title{
Endereço para correspondência
}

\author{
Jéssica Alves de Lima Germine \\ Universidade Federal do ABC, Centro de Engenharia, Modelagem e Ciências Sociais Aplicadas \\ Alameda da Universidade s/n, Bairro Anchieta \\ 09606-045 - São Bernardo do Campo-SP, Brasil \\ Roberta Guimarães Peres \\ Universidade Federal do ABC, Centro de Engenharia, Modelagem e Ciências Sociais Aplicadas \\ Alameda da Universidade s/n, Bairro Anchieta \\ 09606-045 - São Bernardo do Campo-SP, Brasil
}

\begin{abstract}
Conditional cash transfers and care work: an analysis of Bolsa Familia Program in 2019

Conditional cash transfer programs target vulnerable families and are preferentially paid to women. Feminist criticism regarding such programs argues that directing financial transfers to women reinforces social roles based on the Sexual Division of Labor, which places a burden on women regarding domestic and care work. This paper investigates the relationship between female ownership and the time spent doing care work, comparing women and men who receive and not receive benefits from Bolsa Família Program. To do so, available data from Continuous PNAD from 2019 were analyzed. The results show that female beneficiaries who care for children up to 5 years old spend more hours doing domestic work than all other groups. However, male beneficiaries who care for children in this age group spend less hours in those activities than beneficiaries who do not.
\end{abstract}

Keywords: Cash transfers. Gender inequalities. Housework. Sexual division of labor.

\section{Resumen}

Transferencia de renta condicional y trabajo de cuidado: un análisis del programa Bolsa Familia en 2019

Los programas de transferencia de renta condicional tienen como público objetivo familias en situación de vulnerabilidad y dan preferencia a la titularidad femenina. La crítica feminista en relación con tales programas argumenta que, al direccionar los beneficios hacia las mujeres, los roles sociales basados en la división sexual del trabajo se refuerzan, lo cual genera una sobrecarga femenina en relación con el trabajo doméstico y de cuidado. Este artículo investiga la relación entre la titularidad femenina y el uso del tiempo en el trabajo de cuidado, comparando mujeres y hombres que reciben y que no reciben prestaciones del programa Bolsa Familia. Para esto, fueron analizados los datos disponibles en la Encuesta Nacional Anual de Muestreo Residencial. Los resultados muestran que las mujeres beneficiadas que cuidan niños de hasta cinco años gastan más horas que todos los otros grupos, aunque los hombres beneficiados que cuidan niños en este rango de edad gastan menos horas que los que no los cuidan.

Palabras clave: Transferencia de renta. Desigualdades de género. Trabajo doméstico. División sexual del trabajo. 